\title{
MISSPECIFICATION VERSUS BUBBLES IN HYPERINFLATION DATA: MONTE CARLO AND INTERWAR EUROPEAN EVIDENCE
}

\author{
Mark A. Hooker \\ Federal Reserve Board, Mail Stop 74 \\ 20th \& C. St. NW \\ Washington, DC 20551 \\ tel. (202) 452-3424 \\ fax (202) 452-2301 \\ mhooker@frb.gov
}

September, 1997

\section{Summary}

This paper analyzes tests of the Cagan hyperinflation-money demand model which have several advantages relative to those in the literature. They do not confound specification error with rational bubbles, are implementable with a linear procedure, and are frequently able to detect periodically collapsing bubbles which have challenged existing tests. After a Monte Carlo analysis, the tests are applied to data from hyperinflations in Austria, Germany, Hungary, and Poland. Strong evidence of model misspecification is found for Austria, while the model with a rational, explosive bubble component well-characterizes the Polish data. Inferences for Germany and Hungary are mixed.

I thank Steven Durlauf, Frank Diebold, two anonymous referees, and seminar participants at Stanford, the Richmond Federal Reserve Bank, Cambridge, Bristol, LSE, and Southampton for helpful comments and discussion on earlier drafts. Chris Edwards provided valuable research assistance. Part of this research was completed at the Federal Reserve Bank of Boston, which I thank for its hospitality. The views expressed do not necessarily represent those of the Federal Reserve Bank of Boston or the Federal Reserve Board of Governors. 


\section{Introduction}

The Cagan model of money demand under hyperinflation (Cagan 1956) has been a workhorse in monetary economics, comparable in its use as a benchmark (and in its geometrically discounted expected value structure) to the dividend-stock price model in financial economics and the permanent income-consumption model in macroeconomics. However, its empirical literature differs in an important way: most papers using the Cagan specification estimate the model's parameters and test particular restrictions, but do not test the overall validity of the model. As Taylor (1991) notes, the Cagan model literature is largely verificationist rather than falsificationist. Perhaps due to this situation, the basic question of whether or not it is a useful model provokes wide disagreement, even when assessed on a common data set. ${ }^{1}$

Part of the confusion is tied to the fact that the Cagan model has multiple equilibria: Explosive, rational bubbles are consistent with the model's solution. In the literature that focuses on bubbles, the validity of the Cagan model is generally a maintained, but untested, hypothesis. Thus direct estimates of bubbles may be biased if the model is misspecified, and tests which regard deviations from the "market fundamentals" solution as evidence of bubbles may be misclassifying specification error. Other strands of the Cagan literature rule out a priori the existence of bubbles, despite potentially serious implications for estimates and tests.

Durlauf and Hooker (1994) developed a methodology for testing the model which does not confound bubbles and specification error. That methodology employs two transformations of the data: under the null of correct specification, one transformation is orthogonal to an information set no matter which of the multiple equilibria obtains, while the other is orthogonal only if the nobubbles equilibrium is realized. Thus sequential application of the tests allows separate falsification of the model's general solution and rational bubble components of that solution. This paper extends that work in three ways.

First, it presents Monte Carlo evidence on the size and power of the tests. Most hyperinflation work, including that of Durlauf and Hooker, uses asymptotic distributions and very short,

\footnotetext{
${ }^{1}$ Most papers estimate the model on the German hyperinflation sample from the early 1920 s.
} 
explosive data samples. As G. Evans (1991) and West (1994) have noted, there is a shortage of evidence on the small-sample performance of tests with explosive data. The tests in this paper may be implemented linearly-using two-stage least squares-which greatly facilitates simulation experiments, in contrast to the many nonlinear and iterative approaches in the hyperinflation literature. Particular attention is paid to the hard-to-detect bubbles described in G. Evans (1991), and alleged to be present in the German hyperinflation and the recent Polish hyperinflation by Blackburn and Sola (1992) and Funke, Hall, and Sola (1994) respectively.

Second, the paper derives estimators of the model's specification error as a time series. The analogy in the term structure literature is the estimated series of term premia rather than just a scalar measure of whether they are nonzero or nonconstant. This added dimension may provide useful information on the nature of the rejections. As Kim (1996) argues in the context of the permanent income hypothesis, measures of specification error are more likely to shed light on the economic magnitudes of the rejections than are test statistics.

Finally, the paper applies the measures and tests to the classic interwar hyperinflations in Austria, Germany, Hungary, and Poland, and compares them to results in the literature.

The paper is organized as follows. Section II reviews the Cagan model and the tests, and derives the noise estimators. Section III contains a discussion of some recent and related literature. In Section IV, Monte Carlo results for test size and power against several potential bubble alternatives are reported. Applications of the tests to the interwar hyperinflation data are presented in section $\mathrm{V}$, and section VI concludes.

\section{The Model, Noise Estimators, and Specification Tests}

The Cagan model is a structural equation for money demand which depends upon the expected inflation rate. The linear form of the model is

$$
m_{t}-p_{t}=\beta+\alpha \mathrm{E}\left[\left(p_{t+1}-p_{t}\right) \mid \Omega_{t}\right]+\varepsilon_{t}
$$

where $m_{t}$ and $p_{t}$ are logs of the nominal money supply and price level at time $t, \Omega_{t}$ is an information set comprised of variables that agents use to form time $t$ expectations of time $t+1$ 
prices, $\beta$ is an unrestricted constant term, $\alpha$ is a constant less than 0 , and $\varepsilon_{t}$ is a stochastic money demand disturbance. The parameter $\alpha$ is the (semi-) elasticity of real money demand with respect to inflation, and is often the focus of attention in the Cagan model. Other factors conventionally assigned a role in money demand, like interest rates and income, are assumed to be of secondary importance relative to inflation and satisfactorily captured in the constant and stochastic disturbance terms.

It is customary to substitute forward recursively in (1) and express it in terms of the current price level. Further imposing the transversality condition (that the discounted expectation of the limiting future price goes to zero) yields the fundamental price solution,

$$
p_{t}^{f} \equiv-\beta+\frac{1}{1-\alpha} \sum_{j=0}^{\infty}\left(\frac{\alpha}{\alpha-1}\right)^{j}\left[\mathrm{E}\left(m_{t+j} \mid \Omega_{t}\right)-\mathrm{E}\left(\varepsilon_{t+j} \mid \Omega_{t}\right)\right]
$$

it depends upon the expected sequence of current and future money supply levels and money demand disturbances. The general price solution. which we denote $p_{t}^{g}$, does not impose the transversality condition. The set of general solutions is infinite-dimensional; members may be obtained by adding any "bubble" process $b_{t}$ which satisfies

$$
b_{t}=\frac{\alpha}{\alpha-1} \mathrm{E}\left(b_{t+1} \mid \Omega_{t}\right)
$$

to the fundamental price solution. The bubbles may be thought of as indexing the solutions, with $b_{t}=0$ for all $t$ corresponding to the fundamental solution.

Observed price level data may be partitioned into three components. They may behave according to the fundamental solution, may also contain a nonzero bubble component, and may contain elements inconsistent with the general solution. These three elements define an unobserved components identity:

$$
p_{t} \equiv p_{t}^{f}+b_{t}+s_{t},
$$

where $s_{t}$ denotes specification error (which we also refer to as model noise). It is this last term, and its implications for estimates and tests, which has been ignored in most of the Cagan model 
literature. Durlauf and Hooker (1994) used transformations of (4) and its orthogonality properties under rational expectations to generate tests of whether $s_{t}$ and $b_{t}$ are nonzero.

These transformations use the perfect foresight fundamental price first employed by Shiller and Siegel (1977) in another context:

$$
p_{t}^{*} \equiv-\beta+\frac{1}{1-\alpha} \sum_{j=0}^{\infty}\left(\frac{\alpha}{\alpha-1}\right)^{j}\left(m_{t+j}-\varepsilon_{t+j}\right)
$$

Since $\mathrm{E}\left(p_{t}^{*} \mid \Omega_{t}\right)=p_{t}^{f}$, the difference between the fundamental and perfect foresight fundamental price is orthogonal to $\Omega_{t}$. Denoting that forecast error $v_{t} \equiv p_{t}^{f}-p_{t}^{*}$ and substituting into (4) yields

$$
p_{t}-p_{t}^{*}=v_{t}+b_{t}+s_{t}
$$

the first transformation of (4). Applying the forward quasi-difference operator $\Phi \equiv-\left(1-\frac{\alpha}{\alpha-1} L^{-1}\right)$ to (6) eliminates the predictable part of the bubble term and yields

$$
r_{t+1} \equiv \Phi\left(p_{t}-p_{t}^{*}\right)=\Phi\left(v_{t}\right)+\frac{\alpha}{\alpha-1} \xi_{t+1}+\Phi\left(s_{t}\right)
$$

the second transformation of (4); $\xi_{t+1}$ is the innovation in the bubble process.

The term $r_{t+1}$ has three components, as may be seen from the right-hand side of (7). The first two of these are orthogonal to $\Omega_{t}$ by definition: $\Phi\left(v_{t}\right)$ is the difference of a period $t$ forecast error and a (coefficient times a) period $t+1$ forecast error, while the second component is the same coefficient times the next period's bubble innovation. The final component is a transformation of the model's specification error. It cannot be orthogonal to $\Omega_{t}$ unless $s_{t}$ itself is, because the transformation is exactly the inverse of the bubble growth rate-implying that if $s_{t}$ is nonzero and $\Phi\left(s_{t}\right) \perp \Omega_{t}$, then $s_{t}$ grows at the rate of (and thus is observationally equivalent to) a bubble. In terms of the variables in (1), $r_{t+1}$ may be written

$$
r_{t+1}=\frac{\alpha}{\alpha-1} p_{t+1}-p_{t}+\frac{1}{1-\alpha} m_{t}-\frac{1}{1-\alpha} \varepsilon_{t} .
$$




\section{A. Specification Tests}

The specification tests are based on the orthogonality properties of $p_{t}-p_{t}^{*}$ and $r_{t+1}{ }^{2}$ Projections of $p_{t}-p_{t}^{*}$ onto time-t information sets, which are referred to as stock tests, give measures of $b_{t}+s_{t}$. Projections of $r_{t+1}$ onto the same information sets, called flow tests, give measures of (a transformation of) model noise, $\Phi\left(s_{t}\right)$. If the correlations of $p_{t}-p_{t}^{*}$ and $r_{t+1}$ with the information sets are both statistically indistinguishable from zero, then we may conclude that the price series obeys the fundamental solution. If the $p_{t}-p_{t}^{*}$ projection is nonzero while the $r_{t+1}$ projection is zero, that is evidence for the presence of a bubble. If the $r_{t+1}$ projection is nonzero, then the $p_{t}-p_{t}^{*}$ projection should be as well; in this case misspecification is present and further analysis is required to determine whether an explosive component exists in addition to $s_{t}{ }^{3}$ These two types of projections, therefore, permit discrimination between different types of violations of the fundamental price solution, and, as shown in Durlauf and Hooker (1994), contain all of the time-series implications of the general and fundamental null hypotheses. ${ }^{4}$

Projections of $p_{t}-p_{t}^{*}$ and $r_{t+1}$ cannot be directly implemented because $\varepsilon_{t}$ is unobserved, and the sum in (5) is infinite. We work with their observable analogs:

$$
h_{t+1}=\frac{\alpha}{\alpha-1} p_{t+1}-p_{t}+\frac{1}{1-\alpha} m_{t}=r_{t+1}+\frac{1}{1-\alpha} \varepsilon_{t}
$$

and

$$
p_{t}^{\prime}=\frac{1}{1-\alpha} \sum_{j=0}^{T-t-1}\left(\frac{\alpha}{\alpha-1}\right)^{j} m_{t+j}+\left(\frac{\alpha}{\alpha-1}\right)^{T-t} p_{T}
$$

\footnotetext{
${ }^{2}$ It should be noted if private agents observe a larger information set than do econometricians, then $p_{t}-p_{t}^{*}$ and $r_{t+1}$ are not necessarily orthogonal to agents' information sets, but are orthogonal to the econometrician's information set (Sargent 1987 p. 334-335).

${ }^{3}$ If the prices differ from the general solution by an explosive amount, we might call that a bubble but not a rational bubble.

${ }^{4}$ That paper contains proofs of the consistency of the tests, and conditions under which lagged prices must be included in the information set to detect a bubble.
} 
that is, we ignore $\varepsilon_{t}$ and approximate (5) by truncating the sum. ${ }^{5}$ The tests use transformations of $h_{t+1}$ and $p_{t}-p_{t}^{\prime}$ which retain the orthogonality properties of $p_{t}-p_{t}^{*}$ and $r_{t+1}$ under parametric assumptions on $\varepsilon_{t}$.

We choose two important and common identifying assumptions about $\varepsilon_{t}$ : first. that it is equal to zero for all $t$, referred to as the exact case, and second, where it follows a random walk $\left(\varepsilon_{t}=\varepsilon_{t-1}\right.$ $+u_{t}$ with $\left.u_{t} \perp \Omega_{t-1}\right)$. The exact specification has been employed by Goodfriend (1982); the related permanent income and dividend-stock price models are exact as well. While it is probably overly restrictive, this case provides a useful benchmark. The random walk is the standard specification in the literature, although its use is controversial. P. Evans (1978) gives an economic justification, while several authors provide statistical support (mostly based on the autocorrelation of residuals). Taylor (1991) has criticized this specification, noting that it implies that prices and fundamentals are not cointegrated even when a bubble is not present, while Christiano (1987) forcefully makes the point that "decisions about how to model disturbance terms can have a significant impact on parameter estimates."

In the exact case, where $\varepsilon_{t}=0$ for all $t, h_{t+1}=r_{t+1}$, so no transformation is necessary. Similarly, $p_{t}-p_{t}^{\prime}$ equals $p_{t}-p_{t}^{*}$ up to the truncation approximation. Under the random walk assumption, $h_{t+1}$ is not necessarily orthogonal to $\Omega_{t}$, because it involves $\varepsilon_{t}$ which is a function of past data. However, the problem may be solved by differencing:

$$
\Delta h_{t+1}=\Delta\left(r_{t+1}+\frac{1}{1-\alpha} \varepsilon_{t}\right)=\Delta \Phi\left(v_{t}\right)+\Delta \frac{\alpha}{\alpha-1} \xi_{t+1}+\Delta \Phi\left(s_{t}\right)+\frac{1}{1-\alpha} u_{t}
$$

$\Delta h_{t+1}$ may then be regressed against elements of $\Omega_{t-1}$ to test for specification error relative to the model's general solution when $\varepsilon_{t}$ follows a random walk. ${ }^{6}$ Note that in the random walk case, the

\footnotetext{
${ }^{5}$ We also ignore the constant term in (10); in the tests, an unrestricted constant term is included in the information set. While $p_{t}^{\prime}$ is constructed using all available money and price data ( $T$ is the last observation available), in the tests $t$ ranges only across the pre-monetary reform observations. Regime issues are discussed below.

${ }^{6}$ In the particular case where specification error too follows a random walk, the test will fail to detect it-as will any test based on the covariance structure of the data-because it is observationally equivalent to the disturbance in the model (1). One implication, stressed by Hamilton and Whiteman (1985) and others, is that it is impossible to distinguish between unobservable fundamentals which have the same structure as either specification error or bubbles. The approach taken in this paper, and in the majority of the Cagan model literature, is to make parametric error process assumptions and to test them as part of the model.
} 
information set must be lagged, as contemporaneous variables are correlated with $\Delta h_{t+1}$ under the null. It should be noted here that more general, but still parametric, cases could be handled in similar ways. For example, if $\Delta \varepsilon_{t}$ followed a finite order MA process, the information set would need to be lagged accordingly, and if $\Delta \varepsilon_{t}$ followed an AR process, then (11) could be appropriately quasi-differenced and those parameters estimated along with $\alpha$.

Similarly, in the random walk case $p_{t}-p_{t}^{\prime}$ is not necessarily orthogonal to $\Omega_{t}$, because it too involves $\varepsilon_{t}$. Again the problem may be solved by differencing:

$$
\Delta p_{t}-\Delta p_{t}^{\prime} \approx \Delta v_{t}+\Delta b_{t}+\Delta s_{t}-\frac{1}{1-\alpha} \sum_{j=0}^{\infty}\left(\frac{\alpha}{\alpha-1}\right)^{j} u_{t+j}
$$

is orthogonal to $\Omega_{t-1}$ under the fundamental null hypothesis. Each of these projection terms, $p_{t}-p_{t}^{\prime}$ and $h_{t+1}$ and their first differences, may then be constructed given estimates of the model parameters $\alpha$ and $\beta$.

In studying hyperinflation episodes, the issue of monetary regime changes and coefficient instability arises. One way of dealing with this is to model the regimes, as Blackburn and Sola (1992) do using a Markov switching process. We follow the majority of the literature in simply truncating the data samples before expectations of a regime change become significant, with the exception that our $p_{t}-p_{t}^{\prime}$ series are constructed using the entire sample, including post-monetary reform data. Two lines of reasoning support this practice: First, Flood and Hodrick (1986) demonstrate that if the terminal value in the construction of $p_{t}-p_{t}^{\prime}$ contains a bubble, then the bubble will be exactly canceled out and stock tests will never reveal it. However, in all cases the hyperinflations either end or moderate, so it is unlikely that a bubble exists in the terminal value. Second, the estimates of $\alpha$ imply very heavy discounting of future values of money and prices: for instance, with $\alpha=-3$ the discount factor is only 0.75 , which weights observations 48 months out by $10^{-6}$. By contrast, the discount factor for monthly data is near unity in most finance and macroeconomics applications. 
The empirical representations of the $p_{t}-p_{t}^{*}$ and $r_{t+1}$ projections onto $\Omega_{t}$ are then regressions of the objects above $-p_{t}-p_{t}^{\prime}$ and $h_{t+1}$ in the exact case, and $\Delta p_{t}-\Delta p_{t}^{\prime}$ and $\Delta h_{t+1}$ in the random walk case-on constants, lags of (differences of) money and prices, and possibly other information assumed to be in $\Omega_{t}$. We estimate $\alpha$ and $\beta$ via GMM. using the flow projections themselves as the orthogonality conditions, and by instrumental variables. The tests are of the Wald form for the null hypothesis that all nonconstant regression coefficients equal zero. It is important to include lagged prices, because if a bubble exists and the money supply is exogenous, then projections on money may indicate orthogonality when in fact those lagged prices-which are also part of $\Omega_{t}$ are correlated with $p_{t}-p_{t}^{\prime}$ or $\Delta p_{t}-\Delta p_{t}^{\prime}$. In Section IV, Monte Carlo evidence on the performance of these tests is presented.

\section{B. Model Noise Estimators}

The basic idea for estimating model noise is to project $r_{t+1}$ onto an empirical measure of $\Omega_{t}$ to get an estimate of $\Phi\left(s_{t}\right)$, and then to undo the transformation. The inverse of the forward quasidifference operator $\Phi(\cdot)$ gives the geometrically discounted expected future sum of the operand, which can be solved using existing techniques and small modifications. We derive estimators for both the exact and the random walk cases. ${ }^{7}$

\section{Exact Case}

In the exact case, note that

$$
r_{t+1}=h_{t+1}=\Phi\left(v_{t}\right)+\frac{\alpha}{\alpha-1} \xi_{t+1}+\Phi\left(s_{t}\right)
$$

so that by definition

$$
\mathrm{E}\left[r_{t+j+1} \mid \Omega_{t}\right]=\mathrm{E}\left[\left(1-\frac{\alpha}{\alpha-1} L^{-1}\right) s_{t} \mid \Omega_{t}\right]
$$

Applying the inverse forward quasi-difference operator $\Phi^{-1}(\cdot)$ to both sides (and exchanging the order of integration with the expectations operator) yields

\footnotetext{
${ }^{7}$ The idea of measuring model noise as an unobserved component in a signal extraction context is due to Durlauf and Hall (1989). See Kim (1996) for an application to the permanent income hypothesis.
} 


$$
\hat{s}_{t}=\sum_{j=0}^{\infty}\left(\frac{\alpha}{\alpha-1}\right)^{j}\left[\mathrm{E} r_{t+j+1} \mid \Omega_{t}\right]=\sum_{j=0}^{\infty}\left(\frac{\alpha}{\alpha-1}\right)^{j}\left[\mathrm{E}\left(\frac{\alpha}{\alpha-1} p_{t+1+j}-p_{t+j}+\frac{1}{1-\alpha} m_{t+j}\right) \mid \Omega_{t}\right]
$$

Expression (15) is a version of a Hansen and Sargent (1980) / Sargent (1987, Ch XI.19) "predicting geometric distributed leads" problem. It is a vector version, since the information set $\Omega_{t}$ generally contains more than one variable, and the first term is nonstandard, as it begins one period forward. Hansen and Sargent derive formulae for expressions like (15) in terms of the elements of $\Omega_{t}$ for the case where the variables in $\Omega_{t}$ follow a vector autoregressive process. Here we also make that VAR assumption.

The second and third terms on the RHS of (15) are standard. Letting $x_{t}=\left[m_{t} p_{t}\right]^{\prime}, \lambda(L) x_{t}=$ $\left(1-\lambda_{1} L-\lambda_{2} L^{2}-\ldots-\lambda_{r} L^{r}\right) x_{t}=\omega_{t}$ be its $r$ th order autoregressive representation, and I denote a conformable identity matrix;

$$
E\left[\sum_{j=0}^{\infty}\left(\frac{\alpha}{\alpha-1}\right)^{j} x_{t+j} \mid x_{t} ; x_{t-1} ; \ldots\right]=\lambda\left(\frac{\alpha}{\alpha-1}\right)^{-1}\left[\mathrm{I}+\sum_{j=1}^{r-1}\left(\sum_{k=j+1}^{r}\left(\frac{\alpha}{\alpha-1}\right)^{k-j} \lambda_{k}\right) L^{j}\right] x_{t}
$$

where $\lambda\left(\frac{\alpha}{\alpha-1}\right)=1-\lambda_{1}\left(\frac{\alpha}{\alpha-1}\right)-\lambda_{2}\left(\frac{\alpha}{\alpha-1}\right)^{2}-\ldots-\lambda_{r}\left(\frac{\alpha}{\alpha-1}\right)^{r}$.

To compute the nonstandard first term on the RHS of (15), let

$$
y_{t}=E\left[\sum_{j=0}^{\infty}\left(\frac{\alpha}{\alpha-1}\right)^{j} x_{t+j} \mid x_{t} ; x_{t-1} ; \ldots\right] \text { and } z_{t}=E\left[\sum_{j=0}^{\infty}\left(\frac{\alpha}{\alpha-1}\right)^{j} x_{t+j+1} \mid x_{t} ; x_{t-1} ; \ldots\right] ;
$$

then $y_{t}=x_{t}+\frac{\alpha}{\alpha-1} \quad z_{t}$, implying $z_{t}=\left(y_{t}-x_{t}\right) /\left(\frac{\alpha}{\alpha-1}\right)$. Thus the first term can be obtained as the second element of

$$
\left.\frac{\alpha-1}{\alpha}\left\{\lambda\left(\frac{\alpha}{\alpha-1}\right)^{-1}-\mathrm{I}+\lambda\left(\frac{\alpha}{\alpha-1}\right)^{-1} \sum_{j=1}^{r-1}\left[\sum_{k=j+1}^{r}\left(\frac{\alpha}{\alpha-1}\right)^{k-j} \lambda_{k}\right]\right\} L^{j}\right) x_{t} .
$$

Summing together the three terms, multiplied by their respective coefficients, yields $\hat{s} t$.

\section{Random Walk Case}

In the random walk case, and parallel to (14), 


$$
\mathrm{E}\left(\Delta h_{t+1} \mid \Omega_{t-1}\right)=\mathrm{E}\left[\Delta \Phi\left(s_{t}\right) \mid \Omega_{t-1}\right],
$$

since $\mathrm{E}\left[\Delta \Phi\left(v_{t}\right) \mid \Omega_{t-1}\right]=\mathrm{E}\left[\Delta \xi_{t+1} \mid \Omega_{t-1}\right]=\mathrm{E}\left[u_{t} \mid \Omega_{t-1}\right]=0$. This implies that $\Delta s_{t}$ can be estimated via

$$
\begin{aligned}
\Delta \hat{s_{t}} & =-\sum_{j=0}^{\infty}\left(\frac{\alpha}{\alpha-1}\right) j\left[\mathrm{E} \Delta h_{t+j+1} \mid \Omega_{t-1}\right] \\
& =-\sum_{j=0}^{\infty}\left(\frac{\alpha}{\alpha-1}\right) j\left\{\mathrm{E}\left[\left(\frac{\alpha}{\alpha-1} \Delta p_{t+1+j}-\Delta p_{t+j}+\frac{1}{1-\alpha} \Delta m_{t+j}\right) \mid \Omega_{t-1}\right]\right\} ;
\end{aligned}
$$

these terms are constructed with estimates of $\alpha$ from the associated orthogonality condition and described above. Equation (19) is another Hansen-Sargent prediction problem, solved in the same way as (15); it yields an estimate of the first difference of $s_{t}$.

\section{Discussion of Related Literature}

The tests outlined above were designed to combine the insights of Hall (1978), that models with expectations yield orthogonality conditions which can be used as specification tests, and of West (1987) and Casella (1989), that a comparison of the general and fundamental solutions could yield a test for bubbles. Durlauf and Hall (1989) demonstrated how to extract estimates of model noise in the exact case, and showed that the variance of the noise series defines a lower bound that may be used in "variance bounds" tests.

The West/Casella procedure compares estimates of the parameter $\alpha$ from the model's general solution to an estimate from the fundamental solution in a Hausman test. In the absence of model noise, it consistently identifies bubbles (although it does require a specification for the money supply series). However, if observed prices contain a nonzero $s_{t}$ component, then both estimates of $\alpha$ may be inconsistent, and thus the test will also be inconsistent. Other tests which interpret deviations from the fundamental solution as evidence of bubbles share this drawback. 
An interesting recent strand of the Cagan model literature which tests for model misspecification was begun by Taylor (1991) and Phylaktis and Taylor $(1992,1993) .{ }^{8}$ Here the fact that the fundamental solution of the model implies cointegration relationships (under reasonable assumptions about the data generating processes) is exploited. This approach has the advantage that it places relatively mild restrictions on expectational errors and money demand innovations (that each is stationary), whereas most of the Cagan model literature includes rationality and parametric error process restrictions in the null hypothesis.

There are prices to be paid for these advantages, however. The main problem is that both stationary components of observed prices which do not fit the model, and nonstationary components unrelated to money that do fit the model (i.e. bubbles), may exist. Testing the model via cointegration will erroneously fail to reject in the former case, while in the latter, no transformation of prices (or money, if it is endogenous as is usually the case) will render them stationary, so cointegration tests are unimplementable. In small samples, differences of explosive data may appear stationary and thus yield misleading results. G. Evans (1991) has shown that some rational bubbles effectively mimic stationary processes, which may confound these two problems.

The difficulty is illustrated by the fact that while the cointegration approach is essentially a formalization of Diba and Grossman's (1984) method, it is given a different interpretation. Diba and Grossman tested for a nonstationary component in the response series (the price of gold in their application) not also in the forcing variable; Hamilton and Whiteman (1985) applied their procedure to the Cagan model and the German hyperinflation. ${ }^{9}$ However, since correct specification is a maintained hypothesis in these papers, the same evidence that the cointegration approach would construe as misspecification is interpreted as a rational bubble. Again, the test is

\footnotetext{
${ }^{8}$ Other papers which test the specification of the model include P. Evans (1978), which estimates ARIMA models for money and prices in the German hyperinflation and compares the processes obtained to those theoretically implied by reasonable assumptions on the data generating process, and Salemi and Sargent (1979) and Christiano (1987), which use likelihood-based tests. Only Salemi and Sargent allows for the possibility of bubbles, and they all use asymptotic critical values in their tests.

${ }^{9}$ Both of these papers were written before the development of cointegration. Campbell and Shiller (1987) and Diba and Grossman (1988) noted that geometric discount-expectations models of this type yield cointegrating relations.
} 
strictly unimplementable and the caveat above applies if in fact there is a bubble and an endogenous money supply.

Thus, overall, we believe that the rational expectations/parametric approach and the cointegration methodology have different advantages and disadvantages, and thus are useful as alternative and complementary procedures.

\section{A Monte Carlo Study of the Specification Tests}

The specification tests developed in Durlauf and Hooker (1994) are asymptotically distributed as $\chi^{2}$ random variables. There are several reasons that one should be concerned about the finite sample properties of these tests, and of hyperinflation model tests more generally. First, the data samples tend to be quite short-for example, the German hyperinflation's 44 pre-reform observations constitute a relatively long dataset. Second, the series are quite explosive; combining the known low power of unit root tests with short data samples means that there is considerable uncertainty about the appropriate degree of differencing or other detrending procedures, ARIMA model specifications, etc. Finally, these and other tests commonly employ two-stage procedures where the sampling error of the test statistic itself is compounded with that from a previous stage's parameter estimation.

In the simulations, we generate data according to the exact and the random walk versions of the Cagan model with an exogenous money supply. The money supply is assumed to be the particular $\operatorname{ARIMA}(1,2,0)$ process from univariate estimation on the German dataset with the parameters given in Table 1. Fundamental prices are then computed from the money supply series via (2), using the Hansen-Sargent formulas for predicting geometric distributed leads. The simulated money supply and fundamental price series are thus both $\mathrm{I}(2){ }^{10}$ The innovation to money demand disturbances (in the random walk case) is taken to be a standard normal variate.

In each replication, the sample length is 50 observations with another 50 used to construct (10); these are set roughly to correspond to the German data set where the numbers are 44 and 40 ,

\footnotetext{
${ }^{10}$ West (1994) suggests that it would be desirable to know how hyperinflation model and bubbles tests perform when the fundamental equilibrium data follow an I(2) process.
} 
respectively. To reflect uncertainty about the correct specification, tests are performed where the information sets consist of first differenced and of second differenced lags of money and prices. We perform our tests on data where prices obey the fundamental solution and fundamental plus bubbles solutions. Two different bubble types are considered, a simple first order autoregressive process which grows at the appropriate rate, and the periodically collapsing bubbles studied in G. Evans (1991).

To determine small-sample critical values, we compute the 90th, 95th, and 99th percentiles of the empirical distributions of the flow and the stock tests, for information sets containing two through four lags of first and second differences of money and prices (see Table 1). Ten thousand replications are performed for each. Table 1 reveals that the empirical distributions deviate significantly from their asymptotic $\chi^{2}$ limits. In the exact case, the first differenced information set tests are quite poorly behaved, with a tendency to very large test statistics as the number of degrees of freedom rises or the distance out in the tail increases. This tendency is exacerbated in the stock test statistics relative to the flow test statistics. With the (appropriate) second differenced information set, the tests are considerably better behaved, although in several cases critical values are more than three times their asymptotic counterparts.

The same pattern of deterioration in the tails and as the number of degrees of freedom increases holds for the random walk tests statistics with first differenced regressors. The critical value for a $10 \%$ test with four elements in the information set is about the asymptotic value of 13.3 in both the flow and stock tests, but the empirical values then range up to two and three times the asymptotic values. Curiously, the test statistics for the random walk case with second differenced regressors are in many cases smaller than their asymptotic values, particularly for the $10 \%$ tests and larger information sets. In the applications in the next section, we focus somewhat more on the better-behaved exact tests with second differenced regressors and random walk tests with first differenced regressors.

Table 2 reports the results of power and Type I error calculations when a nonfundamental solution obtains; here we simulate data adding bubbles to the fundamental solution for prices. 
Each of these experiments is performed for three different actual values of $\alpha$ which are representative of those estimated in the literature and for one thousand replications in each case. In the first section of the table, a standard AR(1) process with coefficient $(\alpha-1) / \alpha$ is added to the fundamental price series, and in the second section periodically collapsing bubbles as studied by G. Evans (1991) are added. These bubbles are the same as the AR(1) bubbles when they are below a threshold; once they cross it they grow at the faster rate $(\alpha-1) / \pi \alpha$ with probability $\pi$ and crash to a mean level below the threshold with probability $(1-\pi) .^{11}$ The tests use the $95 \%$ critical values and 3 lags of second differenced regressors for the information set.

The flow and stock tests together are quite successful at distinguishing a standard bubble in the I(2) data. In $75 \%$ to $99 \%$ of the simulations, the flow test (correctly) fails to reject while the stock test (correctly) rejects. This compares favorably to the simulation results of Diba and Grossman (1988), where unit root tests are applied to bubbles which are assumed to be directly observable. The size is somewhat too small, however, with fewer than $5 \%$ of the flow statistics leading to (false) rejection.

The success of the tests is best illustrated, however, in their ability to detect the periodically collapsing bubbles. G. Evans (1991) showed that when the per-period probability that the bubble does not crash, $\pi$, is less than 0.95 , the Bhargava $N_{1}$ test has virtually no ability to detect collapsing bubbles and the $N_{2}$ tests correctly identify fewer than $12 \%$ of them. ${ }^{12}$ Furthermore, these results assume the bubbles to be directly observed. The $p_{t}-p_{t}^{*} / r_{t+1}$ tests, by contrast, successfully identify bubbles about $50 \%$ of the time when $\pi$ is 0.95 (43\% with $\alpha=-1$, $47 \%$ with

\footnotetext{
${ }^{11}$ In G. Evans (1991), the bubbles have no trend in the sense that the mean level they return to after a crash and the peak levels they reach are constant across time (cf. his Figure 2). When adding such a bubble to a strongly trended series like hyperinflationary prices, the bubble becomes negligible relative to the fundamentals as time passes. In the simulations, we adapt Evans' bubbles by having them crash back to the level of the money supply (which shares the price level's stochastic trend) rather than a constant. The bubbles are generated according to the formulas

$b_{t+1}=[(\alpha-1) / \alpha] b_{t}+\eta_{t+1}$ if $b_{t}<\tau_{t} ; b_{t+1}=\left\{m_{t}+[(\alpha-1) / \pi \alpha] \theta_{t+1}\left(b_{t}-\alpha m_{t} /(\alpha-1)\right\}+\eta_{t+1}\right.$ if $b_{t}>\tau_{t}$. where $\eta_{t}$ is a white noise shock, $\theta_{t}$ is an exogenous i.i.d. Bernoulli process taking the value 1 with probability $\pi$ and 0 with probability $1-\pi$, and $\tau_{t}$ is a finite-variance deviation from $m_{t}$. Most of the interesting variation in these bubbles occurs across values of the two parameters varied in the table, $\alpha$ and $\pi$.

${ }^{12}$ The Bhargava tests used by Diba and Grossman and Evans are unit root tests which allow for rejection of a unit root in favor of either an explosive or a stable alternative. A rejection in favor of the latter would lead to acceptance of the fundamental solution, since it would not affect the order of integration of money or prices.
} 
$\alpha=-3$, and $54 \%$ with $\alpha=-5$ ) while they are an unobserved component of I(2) data. Remarkably, the power of the tests also does not deteriorate as $\pi$ falls except in the $\alpha=-1$ case: with $\alpha=-3$ or 5 , the percentage of correct rejections is between $45 \%$ and $55 \%$ across the full range of values of $\pi$. The size does rise somewhat as $\pi$ falls, with $10-20 \%$ of the bubbles interpreted as noise when the bubbles are crashing every other period or more $(\pi=0.50$ or 0.25$)$. The success of the tests in identifying these bubbles can be explained as follows. Rational bubbles have two salient characteristics: they are explosive, and they follow a particular time-series pattern given by (3). The Bhargava unit roor test focuses on bubbles' explosiveness, and so misses them when they crash often enough to appear stationary. However, the frequent crashes do not sufficiently change the autocorrelation structure, and so can be detected by orthogonality tests.

\section{Empirical Results for Interwar Hyperinflation Data}

Having investigated the performance of the tests, we now turn to an analysis of the data from four interwar hyperinflation episodes, in Austria, Germany, Hungary, and Poland. The source for the data is Young (1925) (the data source used by Sargent (1986)), with the exception of Germany, where we use the data in Flood and Garber (1980). The results reported for Germany are those obtained by Durlauf and Hooker (1994) interpreted here using critical values from the Monte Carlo simulations.

For Austria, the money series consists of notes in circulation and deposits, while the price index is a retail price index of 52 commodities. Their intersection is available from 1921:1-24:6; stabilization was achieved through intervention of the League of Nations and the signing of its Protocols in October 1922, but reactions began in August of that year. Hence the data employed in the tests run from 1921:1-22:7, while the data from 1922:8-24:6 are employed in the construction of (10). For Germany, the available data run from January 1920 until December 1926; the last datapoint unaffected by significant expectations of a regime change is August 1923 (LaHaye 1985). Data from 1923:9 through the end of 1926 are used in the construction of (10). For Hungary, the intersection of money stock (currency and deposits) and prices runs 1921:7-25:3; 
Sargent (1986) identifies 1924:3 as the reform date so that is used as the first out-of-sample period. Finally, the Polish money stock data consist of just currency; the intersection runs 1921:1-24:4 with the reform date taken as January 1924.

\section{A. Specification Tests}

The empirical results for Austria strongly reject the Cagan model with rational expectations in both the exact and random walk error specifications. In the exact case, reported in Table $3 a$, two of the information sets are correlated with the $h_{t+1}$ at the $5 \%$ level and another is at the $10 \%$ level, and all the information sets but one are significantly correlated with $p_{t}-p_{t}^{\prime}$. The rejections of the model in the random walk case, in Table $3 \mathrm{~b}$, are even stronger. The standard errors are quite large, particularly for the exact model, so that in no case could the null hypothesis of $\alpha=0$ be rejected at the 5\% level. There is no evidence that a bubble is present in the data for Austria.

Durlauf and Hooker (1994) showed that using asymptotic critical values implies strong evidence against the model for Germany; the results in Tables 4a and 4b using the empirical critical values are less clear-cut. In the exact specification, the better-behaved tests with second differenced regressors support the existence of a bubble, while in the random walk case, there is some evidence of misspecification and no evidence of a bubble. The estimates of $\alpha$ are also considerably more precise than for Austria, with many of the $t$-ratios above 2 in absolute value.

The results for Hungary are similar to those for Germany: there is some evidence for a bubble in the exact case, and the random walk specification is strongly rejected. However, the standard errors for $\alpha$ are large, with most $t$-ratios in the range of -0.5 to -1.5 .

The evidence for Poland supports the existence of a rational bubble. No significant specification error is detected in either the exact or the random walk case, and with two exceptions the estimated $\alpha$ values are in a narrow range $(-0.87$ to -2.08$)$. By contrast, the fundamental null hypothesis is rejected for nearly all of the information sets. The estimates of $\alpha$ are generally more precise than for Austria and Hungary, but less than for Germany. 
It is instructive to compare these results with some of those obtained by other authors with similar datasets and specifications. Interestingly, the results here are quite different from Christiano's (1987); he found that imposing the random walk error assumption led to large standard errors for the $\alpha$ estimates with German data. However, we do obtain large standard errors with the other data sets, under both error process assumptions.

Salemi and Sargent (1979) and Taylor (1991) tested the Cagan model with similar data sets for each of these four episodes. The former authors employed the same restrictions that we do in the random walk version of the model, although in a VAR/maximum likelihood framework and with some different assumptions about trends. Taylor's test is considerably less restrictive, allowing deviations from rational expectations (as long as the forecasting errors are stationary) and any stationary money demand disturbance as well. It should be noted that acceptance of the random walk version of the model is would correspond to a cointegration-approach rejection, although this result does not obtain for any of the datasets. Similarly, acceptance of the model using the cointegration-approach could be consistent with rejection of either the exact or the random walk version, due to the existence of stationary specification error. ${ }^{13}$

The results for Austria are somewhat contradictory. In contrast to our strong rejection of the model, Salemi and Sargent did not reject the random walk version; they did, however, find that the estimates of $\alpha$ were very imprecise and mostly wrong-signed. Taylor (1991) rejected the model for Austrian data using residual-based cointegration tests but accepted it using a Johansen test.

Salemi and Sargent rejected the model for Germany in most cases; only with their Model 3 representation and second German dataset did they accept the restrictions of the model at conventional significance levels. Taylor found that residual-based tests support the model for Germany, while the Johansen test accepts non-cointegration.

\footnotetext{
${ }^{13}$ Salemi and Sargent (1979) use asymptotic critical values in their analysis. I refer to their tests of rational expectations but not exogeneity of the money supply. Taylor uses both the standard cointegration critical values in Engle and Yoo (1987) and small sample values from Blangiewicz and Charemza (1990). There is considerable disagreement about the the small sample power of cointegration tests, c.f. Engle and Granger (1987), Hakkio and Rush (1991), and Hooker (1993).
} 
Contradictory results are likewise obtained by these authors for Hungary. Salemi and Sargent found that the model with rational expectations is rejected in all cases but one; Taylor found that the residual-based tests provide weak evidence for cointegration, while the Johansen test accepts noncointegration at the $5 \%$ and $10 \%$ levels for his two datasets.

The results of these authors are most consistent with our results in the case of Poland. Salemi and Sargent found that the model fit these data well, and obtained estimates of $\alpha$ and standard errors very close to those in tables $6 \mathrm{a}$ and $6 \mathrm{~b}$. Furthermore, they found explosive e1genvalues in each of their estimations (consistent with the existence of a bubble). Taylor found evidence for cointegration using both residual-based and Johansen tests. Since these latter tests should reject for nonstationary, nonfundamental price components, it may be that the bubble detected by Salemi and Sargent and the $p_{t}-p_{t}^{\prime}$ tests was of the periodically crashing variety.

\section{B. Model Noise Estimates}

Estimates of the model noise component $p_{t}$ are presented in Figures 2a-d. Since the money and price data are quite explosive, the estimated noise is scaled to the price series and their ratio is plotted. This is also the method recommended by Kim (1996) for gauging the economic magnitude of specification error. Estimates are constructed assuming a 6th order VAR specification for the $\left[m_{t} p_{t}\right]^{\prime}$ vector in (16), using the mean estimated value of $\alpha$ across the first and second differenced information sets, respectively.

For Austria, the noise is initially estimated to comprise 12 or $20 \%$ of the price data, according to the two estimates, falling over time so that by halfway through the dataset it is negligible. It then rises briefly, and is again negligible by the end of the sample. The two estimates are quite parallel, with the second differences information set indicating less noise. This is consistent with the flow test results, which rejected more with first differenced information sets. The average size of the noise component is less than $10 \%$ of the price series, suggesting that the Cagan model with rational expectations and a random walk error may be a reasonable representation of the data. The large 
size of the noise component in the first few months corresponds to relatively low and stable rates of inflation, where the Cagan model may be a poorer descriptor.

For Germany, noise estimated using first differences is a relatively steady and large fraction of prices, fluctuating in the range of $30-50 \%$. By contrast, the noise series from second differenced data drops off sharply and is near zero for roughly the last year of the hyperinflation. Again, these results are consistent with the flow test results, and the noise components are again largest in the early months when prices are relatively low and stable. The noise estimates in the Hungary data are much smaller, and exhibit a less marked drift over the sample. The second differences specification generates noise estimates that are nearly zero throughout the sample, and the first differences specification yields noise about $10 \%$ of prices. This supports the model as a useful data description. For Poland, both specification error estimates are in the 5-8\% range, and not very volatile. While the first differences estimate rises above $10 \%$ in the last two observations, the general solution of the model seems to provide a close approximation to the data, strengthening the interpretation of the fundamental solution rejections as evidence of a bubble.

\section{Summary and Conclusions}

This paper has analyzed tests of the Cagan hyperinflation-money demand model which have several advantages relative to those in the literature: They do not confound specification error with rational bubbles, they are implementable with a linear procedure, and they are frequently able to detect the periodically collapsing bubbles which have challenged existing tests and inferences. A Monte Carlo analysis shows that the finite sample properties of the tests may be quite different from their asymptotic counterparts, but that the tests may contain considerable power.

The empirical results show strong evidence of model misspecification for Austria, while the

model with a rational, explosive bubble component well-characterizes the Polish data. Inferences for Germany and Hungary are mixed, varying across specification of the money demand disturbance and the information sets used in the tests. 


\section{References}

Blackburn, K. and M. Sola (1992), 'Market Fundamentals Versus Speculative Bubbles: A New Test Applied to the German Hyperinflation', University of Southampton Discussion Papers in Economics and Econometrics No. 9208.

Blangiewicz, M. and W. Charemza (1990), 'Cointegration in Small Samples: Empirical Percentiles, Drifting Moments, and Customized Testing', Oxford Bulletin of Economics and Statistics, 52, 303-315.

Cagan, P. (1956), 'The Monetary Dynamics of Hyperinflation', in M. Freidman, ed., Studies in the Quantity Theory of Money, University of Chicago Press, Chicago.

Campbell, J. Y. and R. J. Shiller (1987), 'Cointegration and Tests of Present Value Models', Journal of Political Economy, 95, 1062-1088.

Casella, A. (1989), 'Testing for Rational Bubbles with Exogenous or Endogenous Fundamentals: The German Hyperinflation Once More', Journal of Monetary Economics, 24, 109-122.

Christiano, L. J. (1987), 'Cagan's Model of Hyperinflation Under Rational Expectations', International Economic Review , 28, 33-49.

Diba, B. T. and H. I. Grossman (1984), 'Rational Bubbles in the Price of Gold', NBER Working Paper No. 1300.

Diba, B. T. and H. I. Grossman (1988), 'Explosive Rational Bubbles in the Stock Prices?', American Economic Review, 78, 520-530.

Durlauf, S. N. and R. E. Hall (1989), 'Bounds on the Variances of Specification Errors in Models with Expectations', NBER Working Paper No. 2936.

Durlauf, S. N. and M. A. Hooker (1994), 'Misspecification versus Bubbles in the Cagan Hyperinflation Model', in C. Hargreaves (ed.), Non-Stationary Time Series Analysis and Cointegration, Oxford University Press, Oxford.

Engle, R. F. and C. W. J. Granger (1987), 'Cointegration and Error Correction: Representation, Estimation, and Testing', Econometrica, 55, 251-277.

Engle, R. F. and B. S. Yoo (1987), 'Forecasting and Testing in Cointegrated Systems', Journal of Econometrics, 35, 143-159.

Evans, G. W. (1991), 'Pitfalls in Testing for Explosive Bubbles in Asset Prices', American Economic Review, 81, 922-930.

Evans, P. (1978), 'Time-Series Analysis of the German Hyperinflation', International Economic Review , 19, 195-209.

Flood, R. P. and P. M. Garber (1980), 'Market Fundamentals versus Price-Level Bubbles: The First Tests', Journal of Political Economy, 88, 745-770.

Flood, R. P. and R. J. Hodrick (1986), 'Asset Volatility, Bubbles, and Process Switching', Journal of Finance, 41, 831-842.

Funke, M., S. Hall, and M. Sola (1994), 'Rational Bubbles During Poland's Hyperinflation: Implications and Empirical Evidence'. European Economic Review, 38, 1257-1276. 
Goodfriend, M. S. (1982), 'An Alternative Method of Estimating the Cagan Money Demand Function in Hyperinflation Under Rational Expectations', Journal of Monetary Economics, 9, 43-57.

Hakkio, C. S. and M. Rush (1991), 'Cointegration: How Short is the Long Run?', Journal of International Money and Finance, 10, 571-81.

Hall, R. E. (1978), 'Stochastic Implications of the Life Cycle-Permanent Income Hypothesis: Theory and Evidence', Journal of Political Economy, 86. 971-987.

Hamilton, J. D. and C. H. Whiteman (1985), 'The Observable Implications of Self-fulfilling Expectations', Journal of Monetary Economics, 16, 353-973.

Hansen, L. P. and T. J. Sargent (1980), 'Formulating and Estimating Dynamic Linear Rational Expectations Models', Journal of Economic Dynamics and Control, 2, 7-46.

Hooker, M. A. (1993), 'Testing for Cointegration: Power versus Frequency of Observation', Economics Letters, 41, 359-362.

Kim, C. (1996), 'Measuring Deviations from the Permanent Income Hypothesis', International Economic Review, 37, 205-225.

LaHaye, L. (1985), 'Inflation and Currency Reform', Journal of Political Economy, 93, 537-560.

Phylaktis, K. and M. P. Taylor (1992), 'The Monetary Dynamics of Sustained High Inflation', Southern Economic Journal, 58, 610-622.

Phylaktis, K. and M. P. Taylor (1993), 'Money Demand, the Cagan Model and the Inflation Tax: Some Latin American Evidence', Review of Economics and Statistics, 75, 32-37.

Salemi, M. K. and T. J. Sargent (1979), 'The Demand for Money During Hyperinflation Under Rational Expectations: П', International Economic Review, 20, 741-758.

Sargent, T. J. (1986), Rational Expectations and Inflation, Harper \& Row, New York.

Sargent, T. J. (1987), Macroeconomic Theory, Second Edition, Academic Press, Orlando.

Shiller, R. J. and J. J. Seigel (1977), 'The Gibson Paradox and Historical Movements in Real Interest Rates', Journal of Political Economy, 85, 891-907.

Taylor, M. P. (1991), 'The Hyperinflation Model of Money Demand Revisited', Journal of Money, Credit, and Banking, 23, 327-351.

West, K. D. (1987), 'A Specification Test for Speculative Bubbles', Quarterly Journal of Economics, 102, 553-580.

West, K. D. (1994), 'Rational Bubbles During Poland's Hyperinflation: Implications and Empirical Evidence: Comment', European Economic Review, 38, 1282-1285.

Young, J. P. (1925), for the Commission of Gold and Silver Inquiry, the United States Senate, European Currency and Finance, Volumes 1 and 2, U.S. Government Printing Office, Washington. 


\section{Table 1: Critical Values for Wald Flow and Stock Test Statistics}

A. Exact Model Case. 1st Differenced Regressors

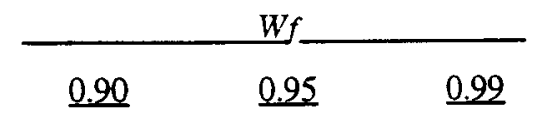

2-lag inf. set

3-lag inf. set

4-lag inf. set

$\begin{array}{rrr}12.97 & 19.87 & 95.90 \\ 23.98 & 39.65 & 311.29 \\ 40.11 & 68.80 & 797.49\end{array}$

\begin{tabular}{rrr} 
& $W s$ & \\
\hline$\underline{0.90}$ & $\underline{0.95}$ & $\underline{0.99}$ \\
48.59 & 88.81 & 1016.44 \\
102.60 & 243.86 & 9542.24 \\
199.39 & 608.77 & 44182.82
\end{tabular}

B. Exact Model Case. 2nd Differenced Regressors

\begin{tabular}{lrrrrrrr} 
& \multicolumn{3}{c}{$W f$} & & & \multicolumn{3}{c}{$W s_{n}$} \\
\cline { 2 - 4 } \cline { 7 - 9 } & $\underline{0.90}$ & $\underline{0.95}$ & $\underline{0.99}$ & & $\underline{0.90}$ & $\underline{0.95}$ & $\underline{0.99}$ \\
2-lag inf. set & 10.58 & 15.14 & 36.59 & & 17.79 & 27.34 & 55.37 \\
3-lag inf. set & 18.23 & 26.32 & 56.24 & & 30.13 & 45.41 & 87.61 \\
4-lag inf. set & 26.85 & 37.56 & 75.80 & & 46.03 & 66.88 & 142.57
\end{tabular}

C. Random Walk Case. 1st Differenced Regressors

\begin{tabular}{|c|c|c|c|c|c|c|}
\hline & \multicolumn{3}{|c|}{$W f$} & \multicolumn{3}{|c|}{$W s$} \\
\hline & 0.90 & 0.95 & $\underline{0.99}$ & 0.90 & 0.95 & 0.99 \\
\hline 2-lag inf. set & 14.62 & 20.23 & 33.92 & 17.34 & 22.90 & 37.28 \\
\hline 3-lag inf. set & 19.44 & 26.59 & 53.70 & 21.98 & 29.96 & 57.80 \\
\hline 4-lag inf. set & 22.78 & 31.52 & 69.01 & 25.66 & 35.43 & 82.52 \\
\hline
\end{tabular}

D. Random Walk Case, 2nd Differenced Regressors

\begin{tabular}{lrrrrrrrr} 
& \multicolumn{3}{c}{$W_{f}$} & & & \multicolumn{3}{c}{$W s$} \\
\cline { 2 - 4 } & $\underline{0.90}$ & $\underline{0.95}$ & $\underline{0.99}$ & & $\underline{0.90}$ & $\underline{0.95}$ & $\underline{0.99}$ \\
2-lag inf. set & 11.14 & 14.80 & 24.70 & & 13.35 & 18.23 & 29.98 \\
3-lag inf. set & 7.91 & 11.48 & 31.19 & & 8.91 & 13.28 & 32.45 \\
4-lag inf. set & 6.37 & 9.46 & 21.47 & & 7.46 & 10.98 & 25.90
\end{tabular}

Notes: Simulations based on 10000 replications of length 50 samples (with an additional 50 out-of-sample observations to construct the stock test). The money supply is an exogenous ARIMA $(1,2,0)$ process with autoregressive coefficient 0.74 , drift equal to 0.02 , and innovation variance 0.12 (estimated from the German univariate data). The fundamental price series is constructed according to equation (2) in the text using HansenSargent prediction formulas for the expectational terms. " $n$-lag information set" refers to the contemporaneous plus $\mathrm{n}-1$ lags of either first or second differences of both money and prices in the exact case, and $\mathrm{n}$ lags in the random walk case; e.g. the $2 \mathrm{lags} / \mathrm{second}$ differences information set for the exact case contains $\Delta^{2} m_{t}, \Delta^{2} p_{t}, \Delta^{2} m_{t-1}$, and $\Delta^{2} p_{t-1} . \alpha$ is estimated using 2 SLS with the information set as instruments. 
Power: \% of replications which accept flow and reject stock test
Type I Error: \% of replications which reject flow test

"Standard" Bubbles

$\begin{array}{lllrrr}\underline{\alpha=-1} & \underline{\alpha=-3} & \underline{\alpha=-5} & \underline{\alpha=-1} & \underline{\alpha=-3} & \underline{\alpha=-5} \\ 75.37 & 99.79 & 99.38 & 5.26 & 0.21 & 0.62\end{array}$

Periodically Collapsing Bubbles

$\begin{array}{lrrrrrr} & \underline{\alpha=-1} & \underline{\alpha=-3} & \underline{\alpha=-5} & \underline{\alpha=-1} & \underline{\alpha=-3} & \underline{\alpha=-5} \\ \pi=.999 & 94.30 & 98.02 & 98.23 & 0.00 & 0.62 & 0.83 \\ \pi=.99 & 70.47 & 81.64 & 82.56 & 0.48 & 2.08 & 3.41 \\ \pi=.95 & 43.43 & 47.26 & 54.18 & 0.66 & 5.69 & 7.43 \\ \pi=.85 & 33.02 & 45.40 & 47.23 & 1.20 & 5.23 & 7.98 \\ \pi=.75 & 31.89 & 47.08 & 48.59 & 2.31 & 5.41 & 9.95 \\ \pi=.50 & 29.56 & 47.02 & 51.11 & 9.12 & 12.34 & 12.04 \\ \pi=.25 & 29.72 & 54.39 & 53.01 & 18.16 & 16.58 & 18.37\end{array}$

Notes: Simulations based on 1000 replications of length 50 samples (with an additional 50 out-of-sample observations to construct the stock test). See Table 1 for construction of the money and fundamental price series. The random walk case, first differences/three lags information is used; $\alpha$ is estimated using 2SLS with that information set as instruments. The standard bubbles are AR(1) processes with coefficient $(\alpha-1) / \alpha$ and shocks $\mathrm{NID}\left(0,1^{2}\right)$; the periodically collapsing bubbles are modified versions of those in Evans (1991) described in foomote 10 of the text. 
Information Set:

First Differences

$\underline{\hat{\alpha}}$

$\underline{\beta}$

$\underline{W} f_{-}$

$\underline{W} s_{-}$

2 lags

$-3.37$

6.38

(14.34)

(18.05)

3 lags

$-5.41$

(30.83)

6.73

(26.21)

4 lags

$-5.37$

(31.05)

6.73

(26.32)

4.80

$67.31 *$

$60.71^{* *}$

$842.29 * *$

rags

\section{(31.05)}

(26.32)

Second Differences

$\underline{\hat{\alpha}}$

$\beta$

$\underline{W}$ -

$\underline{W} s_{-}$

2 lags

0.11

5.64

(9.41)

$74.12 * *$

$3019.59 * *$

3 lags

6.07

-2.14
$(9.26)$

(15.98)

4 lags

$-2.48$

(10.55)

6.10

(16.27)

0.16

1.18

$53.54^{* *}$

$54.98 * *$

24.61

$57.51 *$

Notes: Standard errors, consistent for heteroscedasticity, in parentheses. Information sets consist of the specified number of contemporaneous plus lags of either first or second differences of both money and prices (e.g. the 2 lags/second differences information set contains $\Delta^{2} m_{t}, \Delta^{2} p_{t}, \Delta^{2} m_{t-1}$, and $\left.\Delta^{2} p_{t-1}\right)$. Wf and $W s$ are Wald statistics for the flow and stock tests; asymptotically under the null they have a $\chi^{2}$ distribution with degrees of freedom equal to the number of elements of the information set (two times the number of lags); empirical critical values from simulations on hyperinflation data are given in Table $1 .{ }^{*},{ }^{* *}$, and ${ }^{* * *}$ denote significance at the 10,5 , and $1 \%$ levels. 
Table 3b: Estimates and Tests for Random Walk Model Specification, Austria

Information Ser:

First Differences

$\hat{\alpha}$

$\underline{W}$

$\underline{W} s_{-}$

2 lags

$-0.29$

3.73

2.22

$(0.32)$

3 lags

$-0.82$

$65.45^{* * *}$

$70.84^{* * *}$

4 lags

$(0.47)$

$-1.00$

$27.43^{*}$

$400.73 * * *$

(0.71)

Second Differences

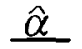

$\underline{W} f_{-}$

$\underline{W} s_{-}$

2 lags

$-0.53$

$(0.52)$

$75.67^{* * *}$

$71.31^{* * *}$

3 lags

$-0.59$

66.78

$66.25^{* * *}$

(0.66)

4 lags

$-0.35$

(0.29)

$283.69 * * *$

$139.45^{* * *}$

Notes: Standard errors, consistent for heteroscedasticity, in parentheses. Information sets consist of the specified number of lags of either first or second differences of both money and prices (e.g. the $2 \mathrm{lags} / \mathrm{second}$ differences information set contains $\Delta^{2} m_{t-1}, \Delta^{2} p_{t-1}, \Delta^{2} m_{t-2}$, and $\left.\Delta^{2} p_{t-2}\right)$. Wf and $W s$ are Wald statistics for the flow and stock tests; asymptotically under the null they have a $\chi^{2}$ distribution with degrees of freedom equal to the number of elements of the information set (two times the number of lags); empirical critical values from simulations on hyperinflation data are given in Table $1 .{ }^{*},{ }^{* *}$, and ${ }^{* * *}$ denote significance at the 10,5 , and $1 \%$ levels. 
Table 4a: Estimates and Tests for Exact Model Specification, Germany

Information Set:

\begin{tabular}{|c|c|c|c|c|}
\hline First Differences & $\underline{\alpha}$ & $\hat{\beta}$ & $\underline{W} f_{-}$ & $\underline{W} s_{-}$ \\
\hline 2 lags & $\begin{array}{l}-4.21 \\
(1.83)\end{array}$ & $\begin{array}{c}1.59 \\
(0.35)\end{array}$ & $15.51 *$ & $58.36^{*}$ \\
\hline 3 lags & $\begin{array}{l}-4.20 \\
(1.76)\end{array}$ & $\begin{array}{c}1.62 \\
(0.36)\end{array}$ & $27.74^{*}$ & 85.49 \\
\hline 4 lags & $\begin{array}{l}-4.36 \\
(1.86)\end{array}$ & $\begin{array}{c}1.68 \\
(0.38)\end{array}$ & $47.80^{*}$ & 77.64 \\
\hline Second Differences & $\underline{\alpha}$ & $\hat{\beta}$ & $\underline{W} f_{-}$ & $\underline{W} s_{-}$ \\
\hline 2 lags & $\begin{array}{l}-1.07 \\
(5.74)\end{array}$ & $\begin{array}{c}1.15 \\
(21.79)\end{array}$ & 0.66 & $48.75^{* *}$ \\
\hline 3 lags & $\begin{array}{l}-1.45 \\
(0.69)\end{array}$ & $\begin{array}{c}1.15 \\
(0.28)\end{array}$ & 7.19 & $170.93 * * *$ \\
\hline 4 lags & $\begin{array}{l}-2.26 \\
(1.08)\end{array}$ & $\begin{array}{c}1.15 \\
(0.31)\end{array}$ & $32.64^{*}$ & $175.96^{* * *}$ \\
\hline
\end{tabular}

Notes: Standard errors, consistent for heteroscedasticity, in parentheses. Information sets consist of the specified number of contemporaneous plus lags of either first or second differences of both money and prices (e.g. the 2 lags/second differences information set contains $\Delta^{2} m_{t}, \Delta^{2} p_{t}, \Delta^{2} m_{t-1}$, and $\left.\Delta^{2} p_{t-1}\right)$. Wf and $W s$ are Wald statistics for the flow and stock tests; asymptotically under the null they have a $\chi^{2}$ distribution with degrees of freedom equal to the number of elements of the information set (two times the number of lags); empirical critical values from simulations on hyperinflation data are given in Table $1 .{ }^{*},{ }^{* *}$, and ${ }^{* * *}$ denote significance at the 10,5 , and $1 \%$ levels. 
Information Set:

First Differences

$\underline{\hat{\alpha}}$

$\underline{W}$

$\underline{W} s_{-}$

2 lags

$-1.30$

8.05

12.48

(0.96)

3 lags

$-0.79$

(0.24)

$28.46^{* *}$

$24.15^{*}$

4 lags

$-0.80$

$30.30^{*}$

24.57

$(0.18)$

Second Differences

$\underline{\hat{\alpha}}$

$-0.75$

$(0.27)$

3 lags

$-0.74$

$(0.54)$

4 lags

$$
-1.03
$$

$(0.21)$
$\underline{W} f_{-}$

$\underline{W} s_{-}$

$14.12^{*}$

6.63

$14.29 * *$

$12.81^{*}$

$26.49 * * *$

$56.84 * * *$

Notes: Standard errors, consistent for heteroscedasticity, in parentheses. Information sets consist of the specified number of lags of either first or second differences of both money and prices (e.g. the 2 lags/second differences information set contains $\Delta^{2} m_{t-1}, \Delta^{2} p_{t-1}, \Delta^{2} m_{t-2}$, and $\Delta^{2} p_{t-2}$ ). Wf and $W s$ are Wald statistics for the flow and stock tests; asymptotically under the null they have a $\chi^{2}$ distribution with degrees of freedom equal to the number of elements of the information set (two times the number of lags); empirical critical values from simulations on hyperinflation data are given in Table $1 . *{ }^{* *}$, and $* * *$ denote significance at the 10.5 , and $1 \%$ levels. 
Table 5a: Estimates and Tests for Exact Model Specification, Hungary

Information Set:

First Differences

$\hat{\alpha}$

$\underline{\beta}$

$\underline{W}_{f-}$

$\underline{W}_{S-}$

2 lags

$-7.91$

1.81

$16.28^{*}$

$110.42 * *$

3 lags

$-8.08$

$(0.69)$

(10.26)

1.79

17.24

$410.73 * *$

4 lags

$-6.29$

(6.23)

(0.66)

1.45

$(0.52)$

17.85

$451.74^{*}$

Second Differences

$\hat{\alpha}$

$\underline{\hat{\beta}}$

$\underline{W}_{f-}$

$\underline{W}_{s}$

2 lags

$-1.29$

(1.43)

0.94

2.88

0.65

3 lags

$-1.24$

(0.37)

(1.38)

0.88

3.49

1.10

4 lags

$-1.30$

(0.35)

6.72

7.18

(1.48)

0.88

$(0.35)$

Notes: Standard errors, consistent for heteroscedasticity, in parentheses. Information sets consist of the specified number of contemporaneous plus lags of either first or second differences of both money and prices (e.g. the 2 lags/second differences information set contains $\Delta^{2} m_{t}, \Delta^{2} p_{t}, \Delta^{2} m_{t-1}$, and $\left.\Delta^{2} p_{t-1}\right)$. Wf and $W s$ are Wald statistics for the flow and stock tests; asymptotically under the null they have a $\chi^{2}$ distribution with degrees of freedom equal to the number of elements of the information set (two times the number of lags); empirical critical values from simulations on hyperinflation data are given in Table $1 .{ }^{*}, * *$, and $* * *$ denote significance at the 10,5 , and $1 \%$ levels. 
Information Set:

First Differences

$\underline{\hat{\alpha}} \quad \underline{W f_{-}} \quad \underline{W s_{-}}$

2 lags

$-1.68$

$27.57^{* *}$

11.14

3 lags

$-1.31$

$28.62^{* *}$

11.62

$(0.84)$

4 lags

$-1.02$

$50.87^{* *}$

22.73

$(0.49)$

Second Differences

$\underline{\alpha}$

$\underline{W}$

$\underline{W}$ -

2 lags

$-0.78$

$21.34^{* *}$

9.86

(0.68)

3 lags

$-0.78$

$50.09^{* * *}$

$17.61 * *$

4 lags

$-1.05$

(0.59)

$34.00 * * *$

$15.61^{* *}$

Notes: Standard errors, consistent for heteroscedasticity, in parentheses. Information sets consist of the specified number of lags of either first or second differences of both money and prices (e.g. the 2 lags/second differences information set contains $\Delta^{2} m_{t-1}, \Delta^{2} p_{t-1}, \Delta^{2} m_{t-2}$, and $\left.\Delta^{2} p_{t-2}\right)$. Wf and $W s$ are Wald statistics for the flow and stock tests; asymptotically under the null they have a $\chi^{2}$ distribution with degrees of freedom equal to the number of elements of the information set (two times the number of lags); empirical critical values from simulations on hyperinflation data are given in Table $1 .{ }^{*},{ }^{* *}$, and $* * *$ denote significance at the 10,5 , and $1 \%$ levels. 


\section{Table 6a: Estimates and Tests for Exact Model Specification. Poland}

Information Set:

\begin{tabular}{|c|c|c|c|c|}
\hline First Differences & $\hat{\alpha}$ & $\underline{\beta}$ & $\underline{W} f_{-}$ & $\underline{W} s_{-}$ \\
\hline 2 lags & $\begin{array}{l}-1.88 \\
(1.16)\end{array}$ & $\begin{array}{c}1.33 \\
(0.35)\end{array}$ & 4.67 & $89.83 * *$ \\
\hline 3 lags & $\begin{array}{l}-1.95 \\
(1.17)\end{array}$ & $\begin{array}{c}1.37 \\
(0.35)\end{array}$ & 6.91 & $131.01^{*}$ \\
\hline 4 lags & $\begin{array}{l}-1.98 \\
(1.21)\end{array}$ & $\begin{array}{c}1.38 \\
(0.36)\end{array}$ & 5.11 & 153.16 \\
\hline Second Differences & $\hat{\alpha}$ & $\underline{\beta}$ & $W f_{-}$ & $\underline{W} s_{-}$ \\
\hline 2 lags & $\begin{array}{l}-1.97 \\
(1.51)\end{array}$ & $\begin{array}{c}1.38 \\
(0.40)\end{array}$ & 1.15 & $20.40^{*}$ \\
\hline 3 lags & $\begin{array}{l}-2.08 \\
(1.52)\end{array}$ & $\begin{array}{c}1.41 \\
(0.39)\end{array}$ & 6.25 & $104.89 * * *$ \\
\hline 4 lags & $\begin{array}{l}-1.86 \\
(1.24)\end{array}$ & $\begin{array}{c}1.33 \\
(0.35)\end{array}$ & 7.46 & $89.22 * *$ \\
\hline
\end{tabular}

Notes: Standard errors, consistent for heteroscedasticity, in parentheses. Information sets consist of the specified number of contemporaneous plus lags of either first or second differences of both money and prices (e.g. the 2 lags/second differences information set contains $\Delta^{2} m_{t}, \Delta^{2} p_{t}, \Delta^{2} m_{t-1}$, and $\Delta^{2} p_{t-1}$ ). Wf and $W s$ are Wald statistics for the flow and stock tests; asymptotically under the null they have a $\chi^{2}$ distribution with degrees of freedom equal to the number of elements of the information set (two times the number of lags); empirical critical values from simulations on hyperinflation data are given in Table $1 .{ }^{*}, * *$, and $* * *$ denote significance at the 10,5, and $1 \%$ levels. 
Information Set:

First Differences

$\underline{\alpha}$

$\underline{W}$ -

$\underline{W} s_{-}$

2 lags

$-0.87$

(1.22)

5.27

9.82

3 lags

$-1.28$

$(1.18)$

11.10

19.69

4 lags

$-5.94$

(8.90)

4.57

$44.78 * *$

Second Differences

$\hat{\alpha}$

$\underline{W} f_{-}$

$\underline{W} s_{-}$

2 lags

$-0.87$

8.00

3 lags

$-1.03$

4.33

7.52

4 lags

Notes: Standard errors, consistent for heteroscedasticity, in parentheses. Information sets consist of the specified number of lags of either first or second differences of both money and prices (e.g. the 2 lags/second differences information set contains $\Delta^{2} m_{t-1}, \Delta^{2} p_{t-1}, \Delta^{2} m_{t-2}$, and $\left.\Delta^{2} p_{t-2}\right)$. Wf and $W s$ are Wald statistics for the flow and stock tests; asymptotically under the null they have a $\chi^{2}$ distribution with degrees of freedom equal to the number of elements of the information set (two times the number of lags); empirical critical values from simulations on hyperinflation data are given in Table $1 .{ }^{*},{ }^{* *}$, and ${ }^{* * *}$ denote significance at the 10.5 . and $1 \%$ levels. 
Figure 1a: Monthly Growth Rates of Price Level and Money Supply, Austria

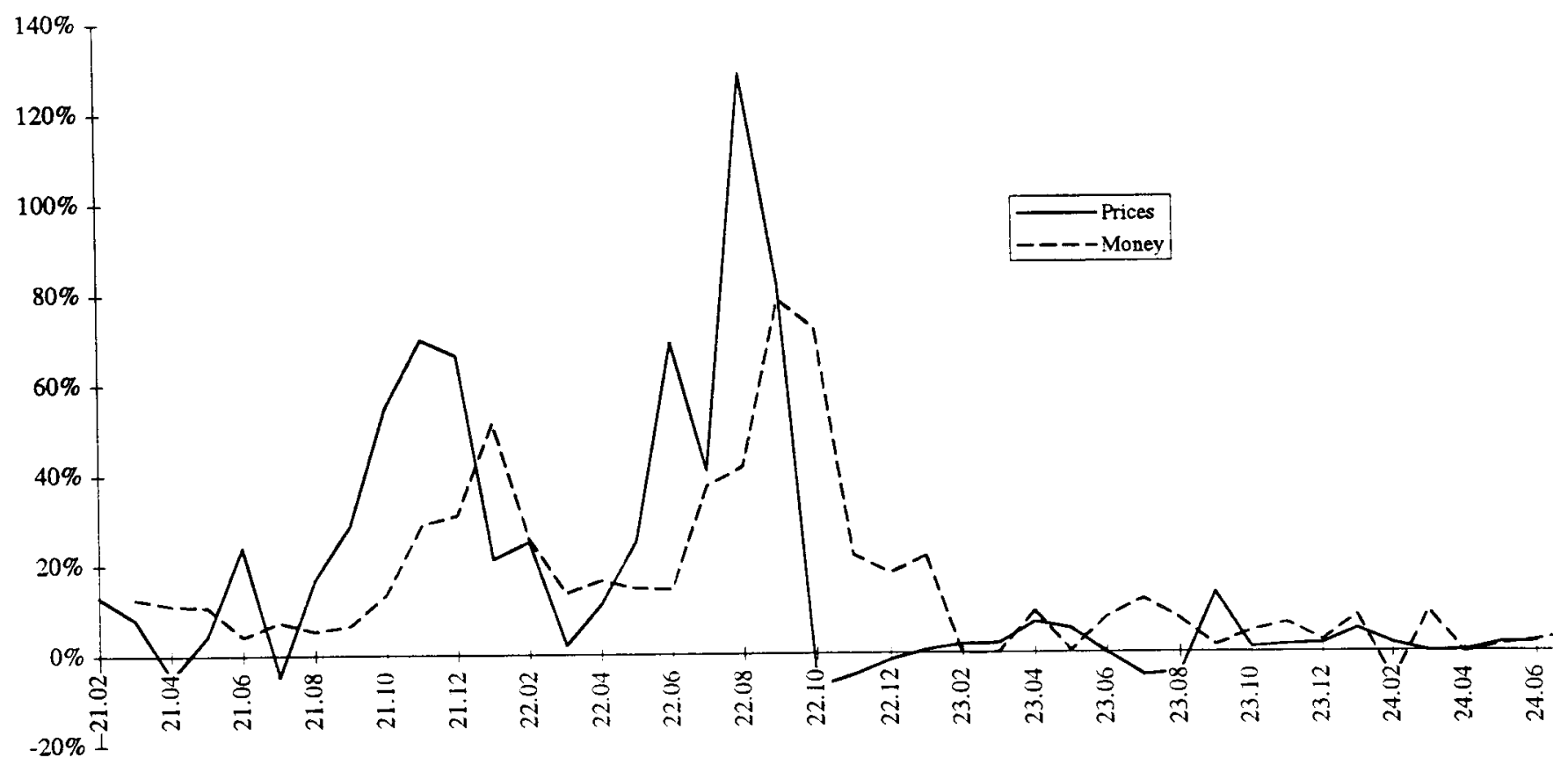

Figure 1b: Monthly Growth Rates of Price Level and Money Supply, Germany

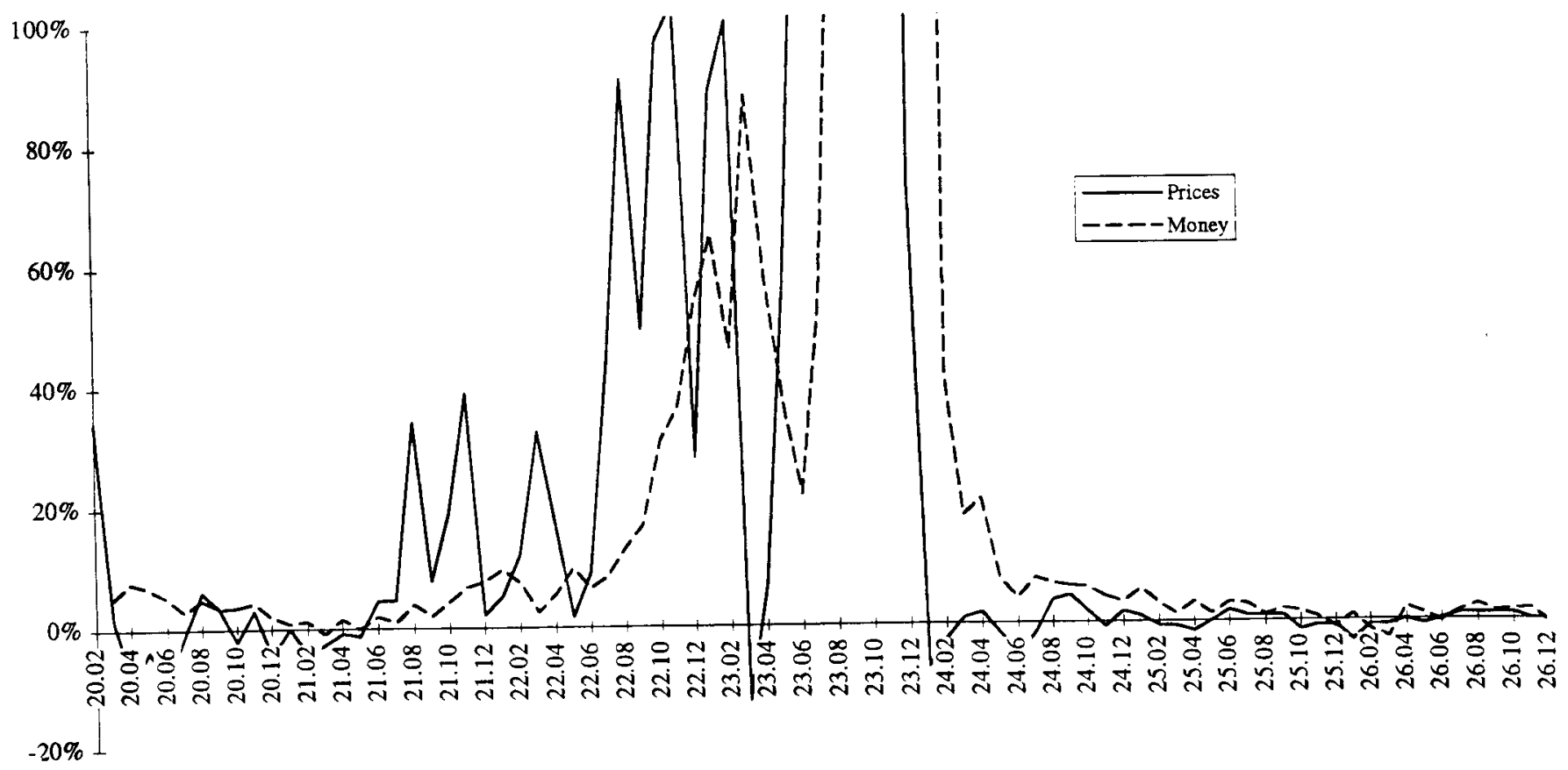


Figure 1c: Monthly Growth Rates of Price Level and Money Supply, Hungary

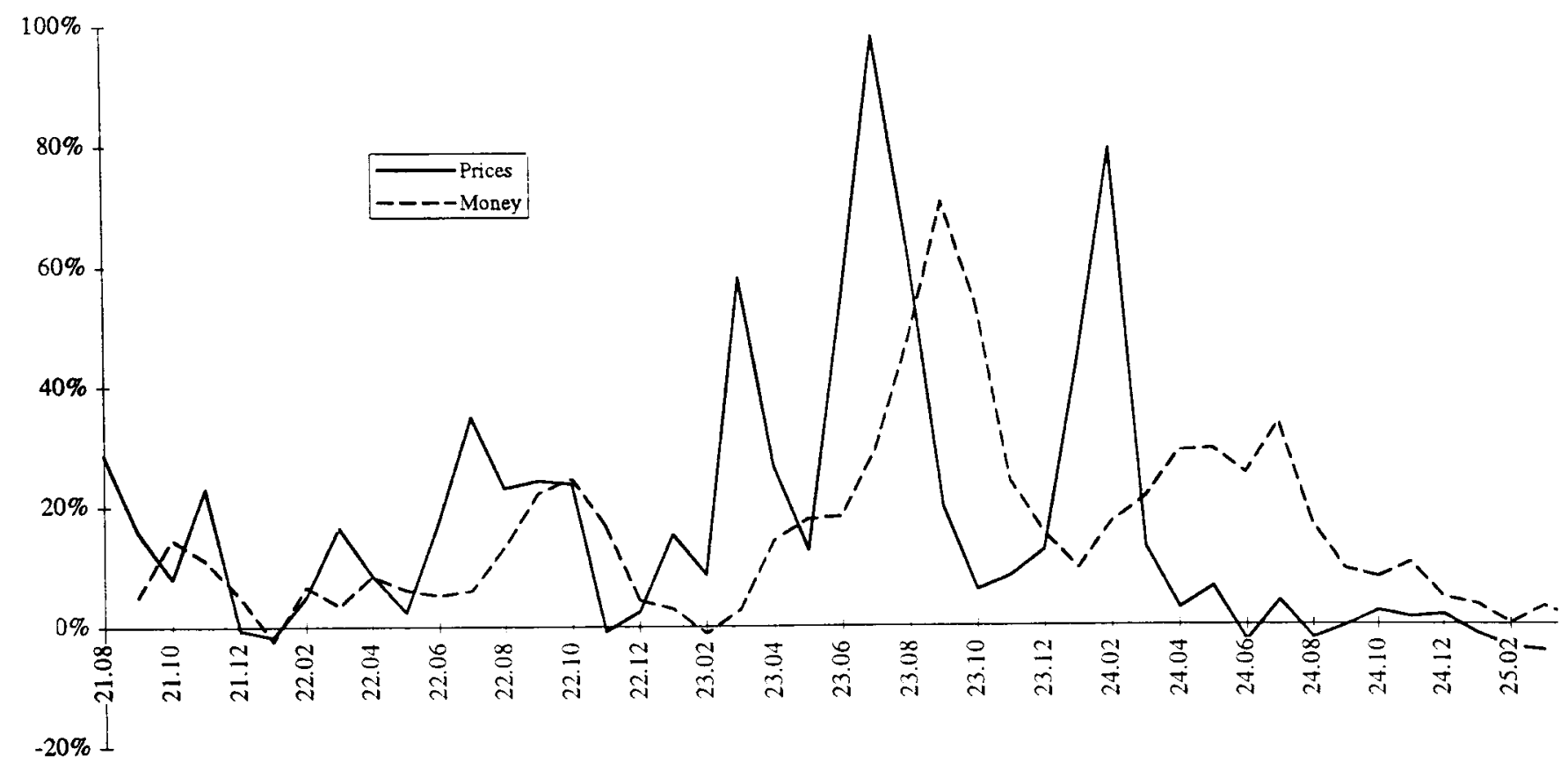

Figure 1d: Monthly Growth Rates of Price Level and Money Supply, Poland

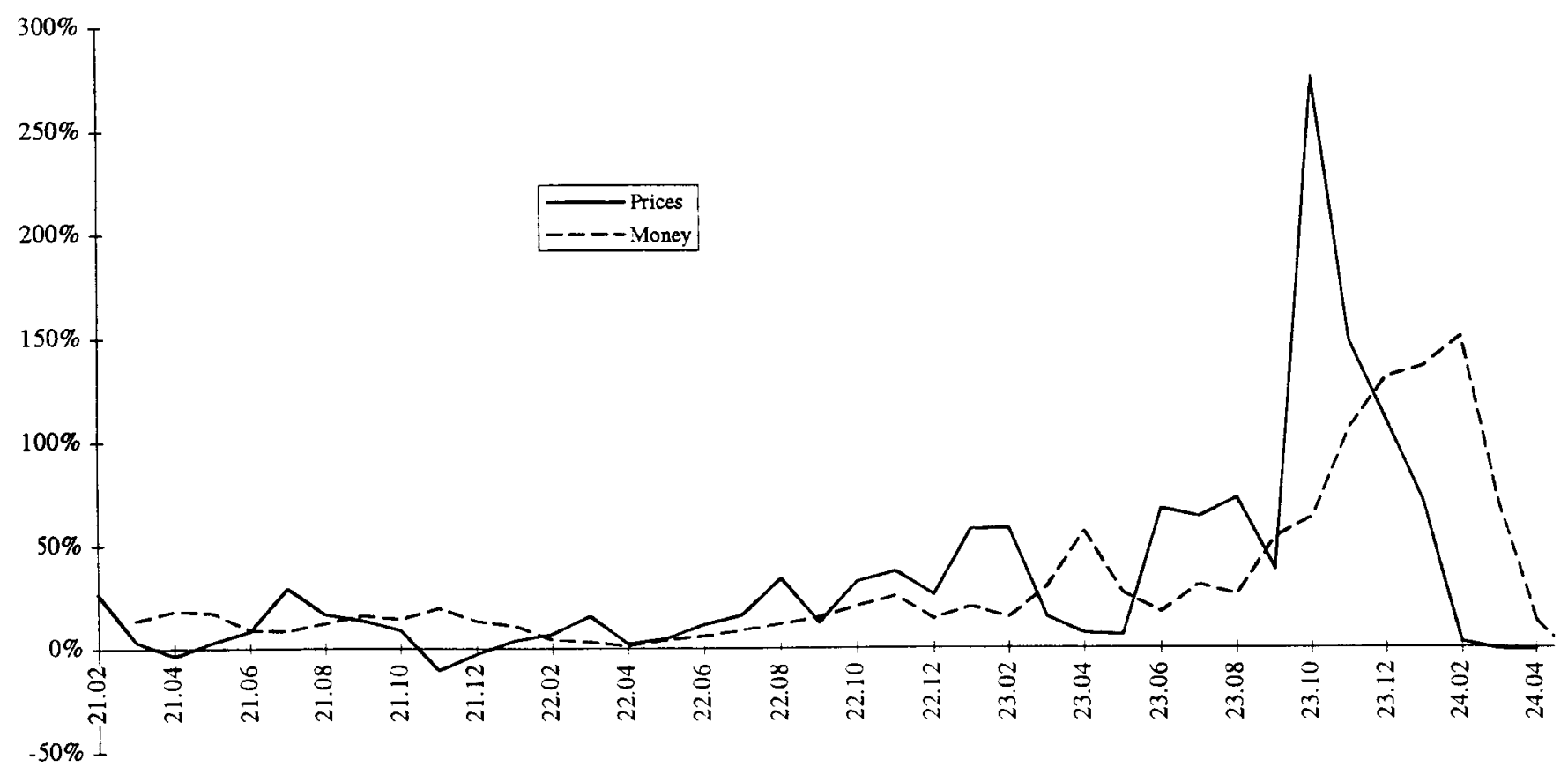


Figure 2a: Ratio of Specification Error to Price Series, Austria

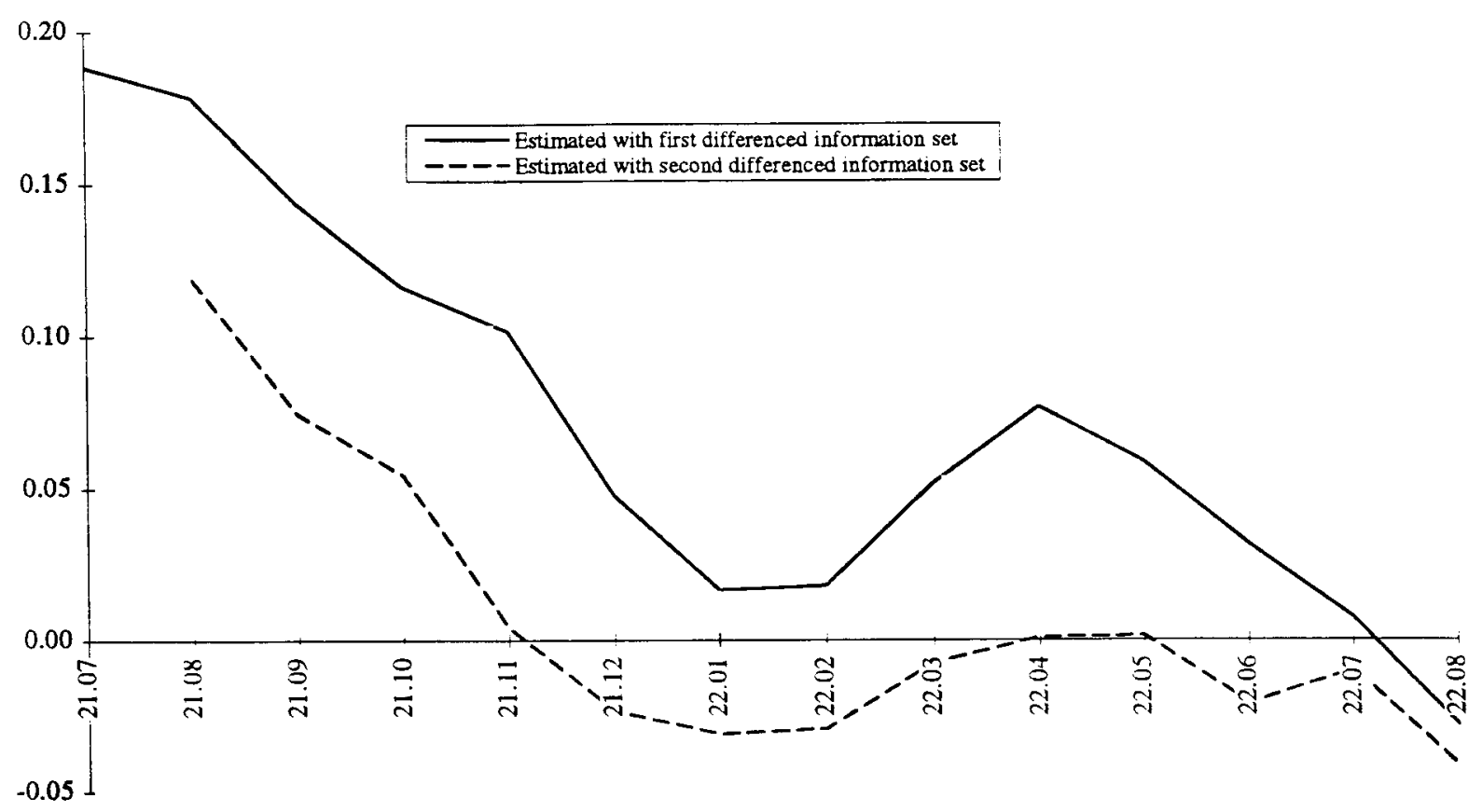

Figure 2b: Ratio of Specification Error to Price Series, Germany

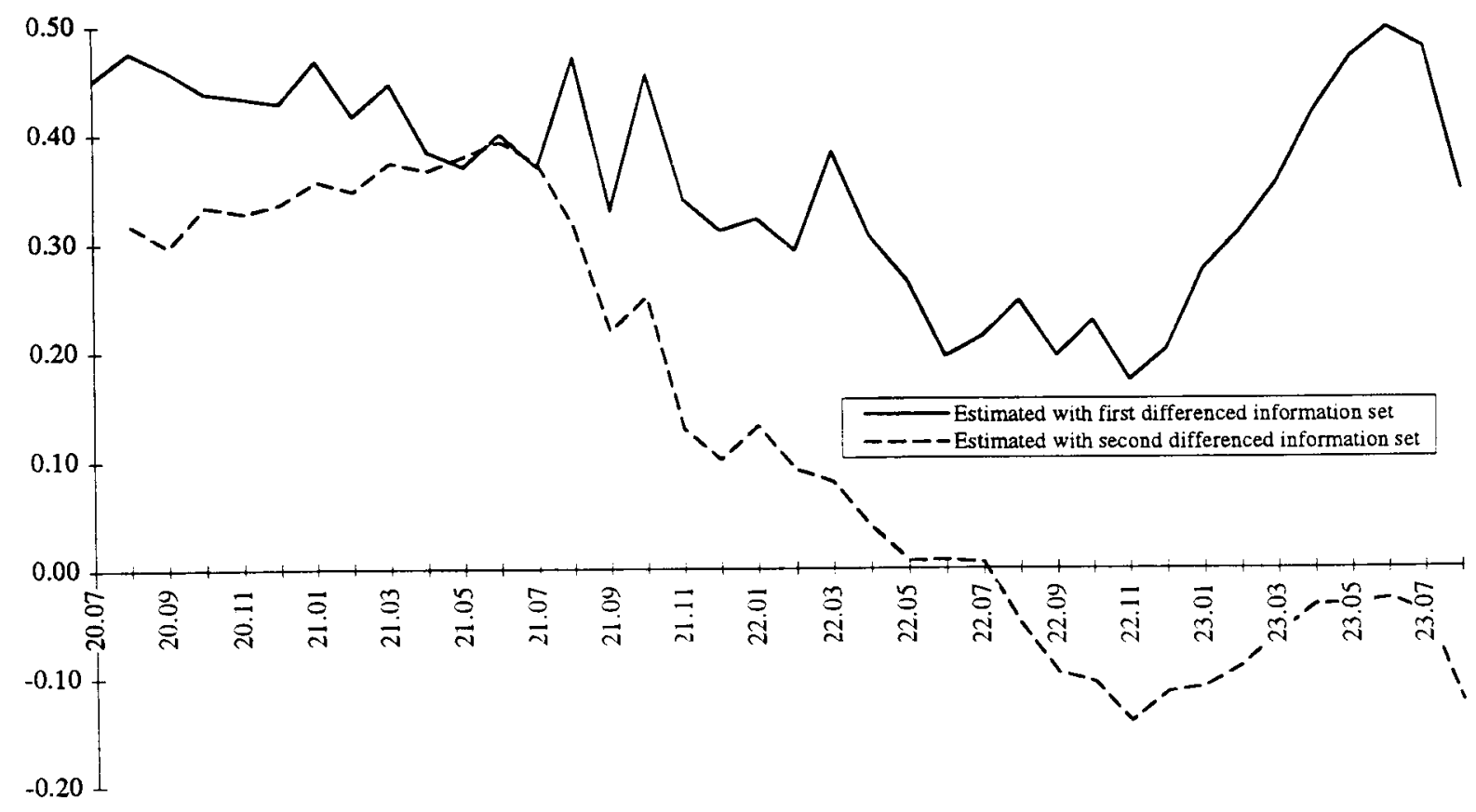


Figure 2c: Ratio of Specification Error to Price Series, Hungary

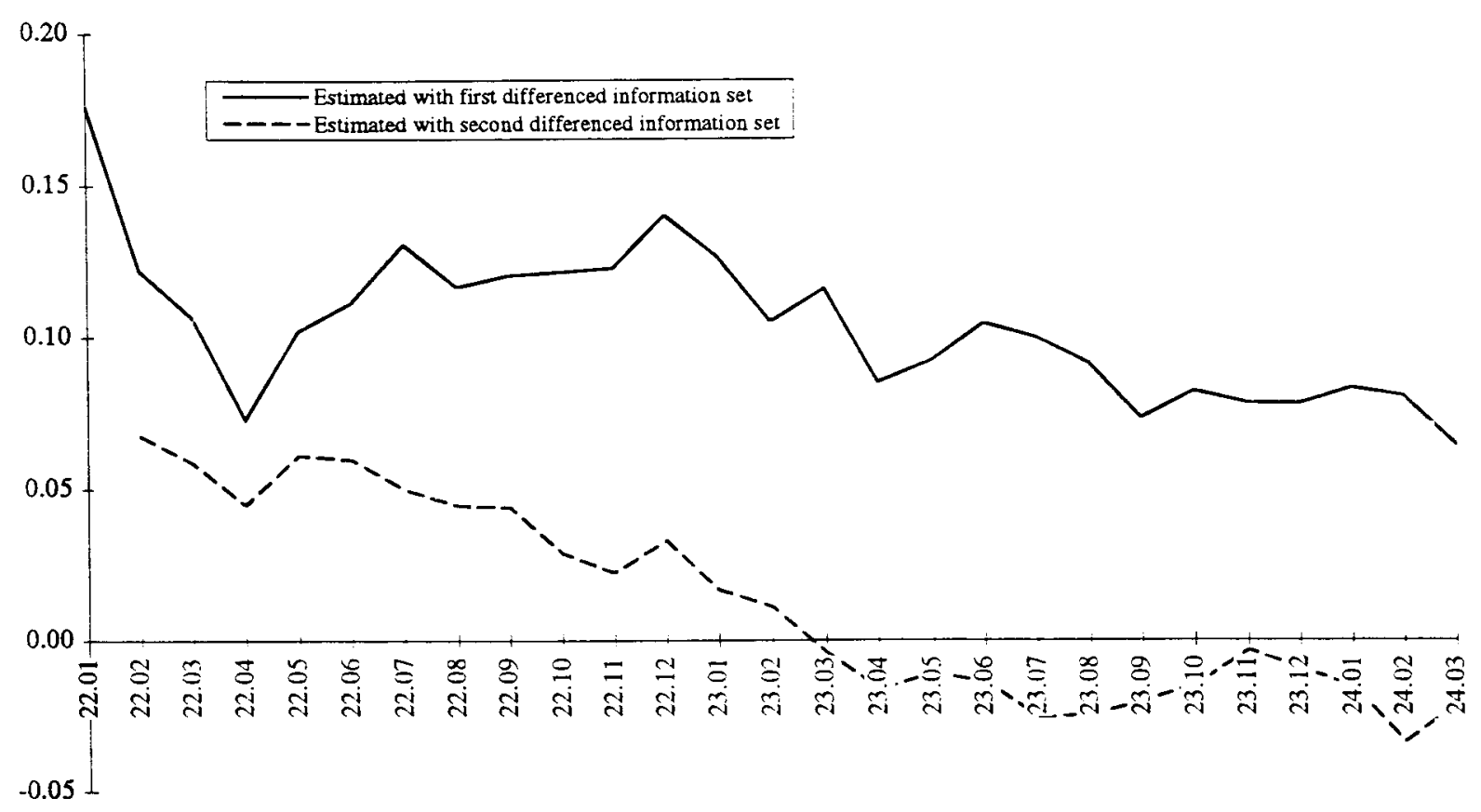

Figure 2d: Ratio of Specification Error to Price Series, Poland

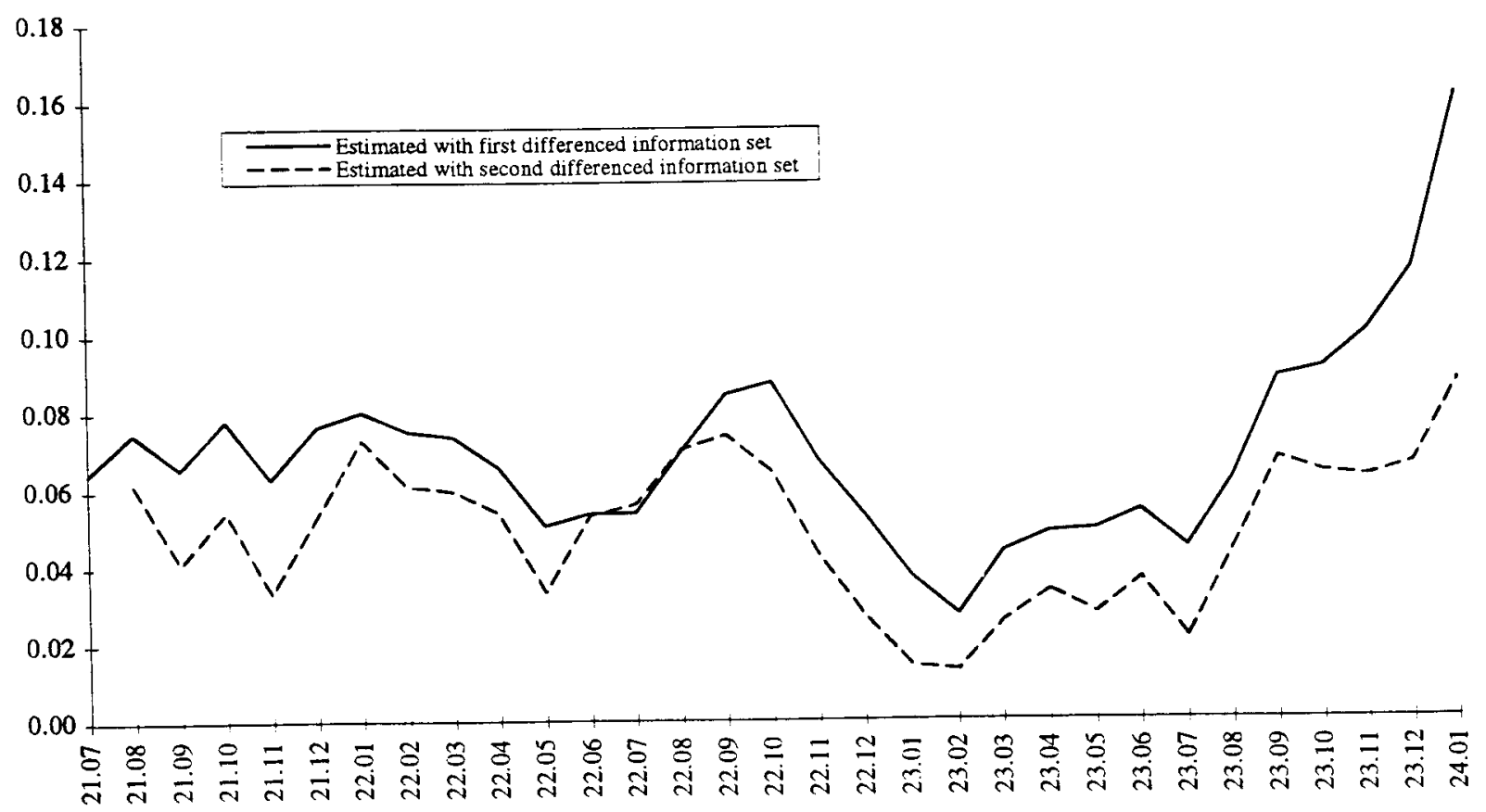

